\title{
Expression of NANOG, but not POU5F1, points to the stem cell potential of primitive germ cells in neonatal pig testis
}

\author{
Sandeep Goel ${ }^{1,2}$, Mayako Fujihara ${ }^{1}$, Naojiro Minami ${ }^{1}$, Masayasu Yamada ${ }^{1}$ and Hiroshi Imai $^{1}$ \\ ${ }^{1}$ Laboratory of Reproductive Biology, Graduate School of Agriculture, Kyoto University, Kyoto 606-8502, Japan and \\ ${ }^{2}$ Centre for Cellular and Molecular Biology, Uppal Road, Hyderabad 500 007, India
}

Correspondence should be addressed to H Imai; Email: imai@kais.kyoto-u.ac.jp

\begin{abstract}
Gonocytes are primitive germ cells that are present in the neonatal testis and are committed to male germline development. Gonocytes differentiate to spermatogonia, which establish and maintain spermatogenesis in the postnatal testis. However, it is unknown whether large animal species have pluripotency-specific proteins in the testis. Nanog and Pou5f1 (Oct3/4) have been identified as transcription factors essential for maintaining pluripotency of embryonic stem cells in mice. Here, we show that NANOG protein was expressed in the germ cells of neonatal pig testes, but was progressively lost with age. NANOG was expressed in most of the lectin Dolichos biflorus agglutinin- and ZBTB16-positive gonocytes, which are known gonocyte-specific markers in pigs. NANOG was also expressed in Sertoli and interstitial cells of neonatal testes. Interestingly, POU5F1 expression was not detected at either the transcript or the protein level in neonatal pig testis. In the prepubertal testis, NANOG and POU5F1 proteins were primarily detected in differentiated germ cells, such as spermatocytes and spermatids, and rarely in undifferentiated spermatogonia. By using a testis transplantation assay, we found that germ cells from 2- to 4-day-old pigs could colonize and proliferate in the testes of the recipient mice, suggesting that primitive germ cells from neonatal pig testes have stem cell potential.
\end{abstract}

Reproduction (2008) 135 785-795

\section{Introduction}

Germ cells are unique cells, which are capable of transmitting genetic information from generation to generation. For this reason, they undergo drastic genetic, epigenetic, and morphological changes through events such as reprogramming, meiosis, and transformation to sperm or oocytes. Most primitive germ cells, that is, primordial germ cells (PGCs), which are bipotential cells that originate from the proximal epiblast, migrate from the base of the allantois via the gut mesentery, and colonize the primitive undifferentiated gonads, where they become gonocytes (Capel 2000, De Rooji \& Russell 2000). Gonocytes are germ cells that reside in the seminiferous tubules of neonatal testes and further differentiate to spermatogonia, thereby initiating spermatogenesis. Therefore, gonocytes are the first cells committed to male germline development and the only germ cells in the neonatal testis. Similarly, in neonatal pig testes, gonocytes are the primary germ cells and spermatogonia are only seen at 2 months of age (Hughes \& Varley 1980). In rats, a specific population of gonocytes has been shown to exhibit stem cell activity, that is, they could generate colonies of spermatogenesis after transplantation into recipient nude mouse testes (Orwig et al. 2002a, 2002 b). In mice, although gonocytes are capable of colonizing recipient testes, they do not proliferate and establish donor-derived spermatogenesis (McLean et al. 2003). However, no study has specifically examined the stem cell capability of gonocytes in a livestock species.

Male germline stem cells have received a great deal of attention in recent years, as it is possible to isolate and culture them in vitro (Nagano et al. 1998, 2000, 2003, Moore et al. 2002, Orwig et al. 2002a, 2002b, Kubota et al. 2004, Hamra et al. 2005, Kanatsu-Shinohara et al. 2005, Guan et al. 2006). These cells can be genetically modified and they further differentiate to spermatozoa following transplantation into a recipient testis, eventually producing transgenic offspring (Nagano et al. 2001, Hamra et al. 2002, Kanatsu-Shinohara et al. 2004a, 2005, 2006). In the case of livestock species, where no embryonic stem (ES) cell line with germline characteristics has been reported to date, a male germ stem cell line could be used to produce transgenic animals in a way that overcomes the numerous shortcomings of the conventional pronuclear injection method. If these cell lines are established, the homologous recombination technique could be applied to create targeted mutated animals. Creation of such animals is presently inefficiently achieved by the somatic cell nuclear transfer technique (McCreath et al. 2000, 
Denning et al. 2001, Lai et al. 2002, Kuroiwa et al. 2004). However, no male germ stem cell line has yet been established for a livestock species. The most probable reason is the lack of sufficient understanding regarding the expression of vital pluripotency-related markers in male germ stem cells. We previously identified a lectin, Dolichos biflorus agglutinin (DBA), as a novel marker for porcine gonocytes and suggested that DBA-binding gonocytes actually represent progenitor-type stem cells in the pig testis (Goel et al. 2007). However, presently, there is no information on the expression of pluripotential markers in the testis of large domestic animals.

Nanog is a homeodomain-bearing transcription factor, which is transcribed specifically in pluripotential stem cells in mouse preimplantation embryos, ES, embryonic germ (EG) and embryonal carcinoma (EC) cells (Chambers et al. 2003, Mitsui et al. 2003, Wang et al. 2003), and monkey and human ES cells (Hart et al. 2004, Hatano et al. 2005). NANOG is required for maintaining pluripotency of cells as shown by the loss of pluripotency in Nanog-deficient ES cells and by the loss of epiblast cells in Nanog-null E5.5 embryos (Mitsui et al. 2003). In the mouse, NANOG expression begins in the compacted morula (Chambers et al. 2003, Hart et al. 2004, Hatano et al. 2005) and is maintained in the epiblast up to E7.5. The expression is quickly downregulated thereafter and only remains in the PGCs (Hatano et al. 2005, Yamaguchi et al. 2005). No germ cells positive for NANOG are present in testes or ovaries of adult mice (Yamaguchi et al. 2005).

Pou5f1 (also known as Oct3/4), a POU and homeobox transcription factor, is essential for maintaining the pluripotential phenotype (Brehm et al. 1998). Pou5f1 is expressed in pluripotential cells of morula, cells of the inner cell mass (ICM), epiblasts, and PGCs (Ovitt \& Schöler 1998). In female PGCs, Pou5f1 is repressed by the onset of meiotic prophase I (E13-14) and is re-expressed after birth, coinciding with the growth phase of oocytes. In male embryos, Pou5f1 expression persists in germ cells throughout fetal development. After birth, it is maintained in proliferating gonocytes, pro-spermatogonia, and later in undifferentiated spermatogonia (Pesce et al. 1998a, Tadokoro et al. 2002). In addition, ES, EG and EC cells, the epiblast, and PGCs also express Pou5f1 as long as they remain undifferentiated (Pesce et al. 1998b, Surani 2001, Donovan \& de Miguel 2003).

In domestic species, the expression of NANOG protein and mRNA has been reported in porcine umbilical cord (PUC) cells cultured in vitro along with other pluripotency-determining factors such as POU5F1 and SOX2 (Carlin et al. 2006). However, these factors were also expressed in the primary fibroblast cell line. In goat preimplantation embryos, while NANOG protein expression is initiated in 8- to 16-cell embryos, POU5F1 expression was first detected at the morula stage and a stronger signal was observed at the blastocyst stage
(He et al. 2006). NANOG and POU5F1 expressions are detected both in the ICM and trophectoderm (TE) of blastocyst-stage goat embryos (He et al. 2006). Similarly, porcine and bovine embryos express POU5F1 protein in ICM and TE of blastocyst-stage embryos (Kirchhof et al. 2000). Whole-mount in situ hybridization of preimplantation bovine blastocysts performed with bovine NANOG cDNA fragments showed that NANOG transcripts were present not only in the germ disc but also in the polar trophoblast cells, which covered the germ disc (Degrelle et al. 2005). In pigs, NANOG transcripts are detected from the four-cell stage onwards to the blastocyst stage in in vivo produced embryos and is significantly downregulated in in vitro-produced and nuclear transfer embryos (Kumar et al. 2007). Transcripts for NANOG, POU5F1, and SOX2 have been detected in ICM, as well as in epiblast cells throughout $96 \mathrm{~h}$ of culture of pig blastocysts in vitro (Blomberg et al. 2007). In chicken, NANOG expression is limited to PGCs in the early embryo and is not detected anywhere in the epiblast (Canon et al. 2006).

The objectives of the present study were to examine the expression of vital pluripotency-determining factors, such as NANOG and POU5F1, in developing postnatal pig testes, and to determine stem cell potential of primitive germ cells from neonatal pig testes using a testis transplantation assay.

\section{Results}

\section{Western blot analysis}

Anti-NANOG and anti-POU5F1 antibodies were able to identify proteins of definite size in the porcine testis lysate as shown by the Western blot analysis (Supplementary Fig. 1, which can be viewed online at www.reproductiononline.org/supplemental/). The protein sizes identified by both the antibodies were higher than their mouse counterparts with the molecular weight of the proteins in the range of $\sim 46-47 \mathrm{kDa}$. However, in case of NANOG immunoblot, a smaller fragment of $\sim 20 \mathrm{kDa}$ was also detected. In POU5F1 immunoblots, no truncated protein was observed.

\section{Histochemistry}

NANOG expression in the neonatal pig testes was present in the germ cells, which are easily distinguished by their size, topological position, and morphology (Fig. 1A). In neonatal testis, the germ cells are easy to distinguish from other cells in the tubules by their large size. However, NANOG expression was observed not only in germ cells of the testis but also in somatic cells such as Sertoli and interstitial cells (Fig. 1A). In sections from 2- to 4-day-old testes, NANOG staining was primarily detected in the nucleus of the stained germ cells and was also weakly detected in the cytoplasm of a few cells (Fig. 1A). 


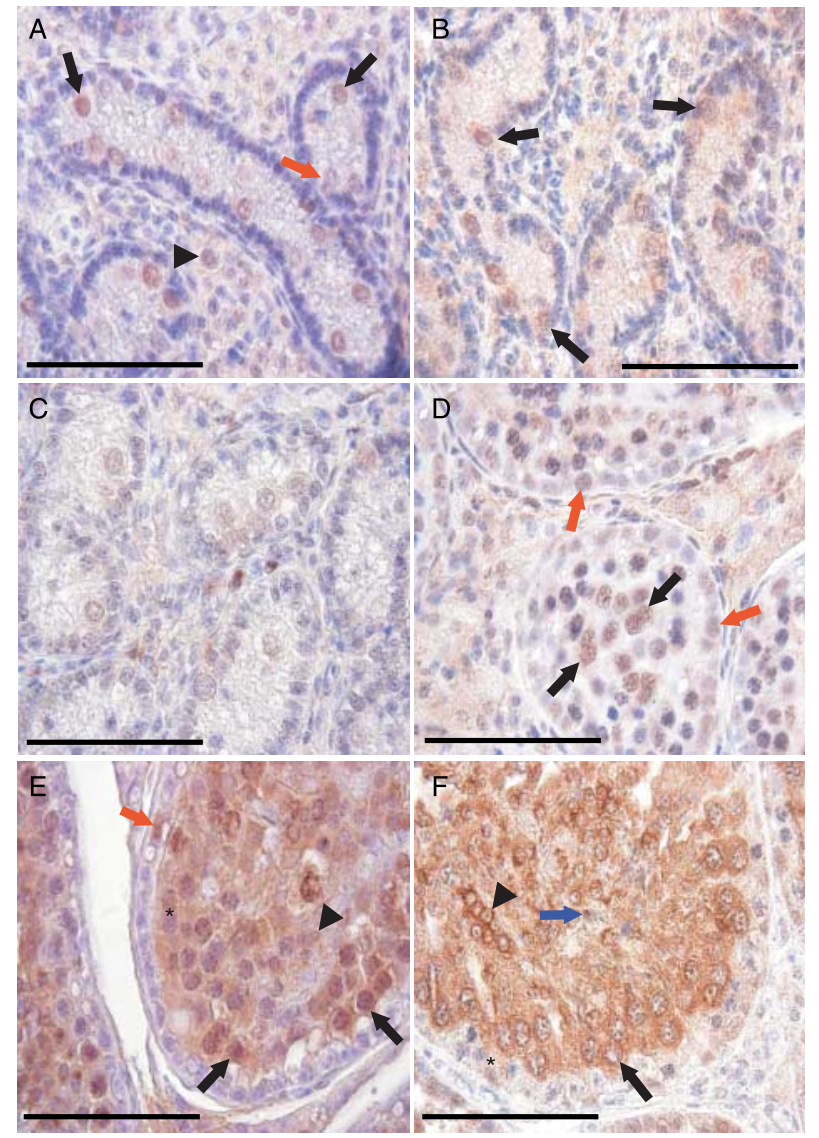

Figure 1 NANOG protein expression in developing postnatal testis sections. (A) In 2-day-old testis section, most germ cells expressed NANOG (black arrows) and a few germ cells did not stain (red arrow). NANOG expression is also seen in Sertoli and interstitial cells (arrowhead). (B) In 1-week-old testis section, many germ cells show perinuclear and cytoplasmic translocalization of NANOG protein (arrows). (C) In 3-week-old testis section, marked reduction of NANOG expression is seen in the germ cells. (D) In 10-week-old testis section, strong NANOG expression is present in spermatocytes (black arrows) and a weak expression is seen in spermatogonia (red arrows). (E) In 20-week-old testis sections, NANOG expression is mostly present in the nuclei of spermatocytes (black arrows). Red arrow indicates a rare, stained spermatogonium. Some spermatocytes show cytoplasmic localization of NANOG (asterisk). NANOG expression is also localized in the cytoplasm of round spermatids (arrowhead) (F) In some tubules of 20-week-old testis sections, spermatocytes only show cytoplasmic localization of NANOG protein (black arrow). Round spermatid (arrowhead) and elongated spermatid (blue arrow) also stained. Asterisk indicates a rare weakly stained spermatogonium. Bar $=50 \mu \mathrm{m}$.

The intensity of NANOG staining in individual germ cells varied and a few germ cells did not stain (Fig. 1A). In 1-week-old testis sections, a large number of germ cells showed perinuclear and cytoplasmic translocalization of NANOG protein (Figs 1B and 2D). NANOG expression in the testicular germ cells decreased progressively with age and in the 2- and 3-week-old testis sections, rarely any germ cell showed strong expression of NANOG protein (Fig. 1C). The intensity of NANOG staining in the germ cells at this age was markedly reduced (Fig. 1C). In 10-week-old testis sections, NANOG was strongly expressed by differentiated germ cells (i.e., spermatocytes) and weak expression was detected in spermatogonia (Fig. 1D). In 20 -week-old testes, NANOG expression was variable in differentiated germ cells, such as spermatocytes and spermatids, and was also weakly detected in a small number of undifferentiated spermatogonia (Fig. 1E and F). Interestingly, NANOG staining varied in the germ cells within tubules in the same section. NANOG expression was observed in the nuclei of most spermatocytes, and following their differentiation to spermatids, it was translocated to the perinuclear region and cytoplasm (Fig. 1E). NANOG staining was also lost from the nuclei of a few spermatocytes (Fig. 1E). In some tubules, NANOG expression in the nuclei of the spermatocytes was absent and it was localized in the cytoplasm, similar to those in round and elongated spermatids (Fig. 1F).

POU5F1 expression was not detected in neonatal testis until 3 weeks of age (Fig. 2A and B). In 10-week-old testes, weak POU5F1 expression was seen in spermatogonia and spermatocytes (Fig. 2C). POU5F1 expression was also detected in the interstitial cells at this age. In 20-week-old testis sections, POU5F1 expression was primarily seen in the nuclei of differentiated germ cells, such as spermatocytes and spermatids, and in a few undifferentiated spermatogonia (Fig. 2D). In the germ cell cytoplasm, POU5F1 staining was weaker than NANOG staining.

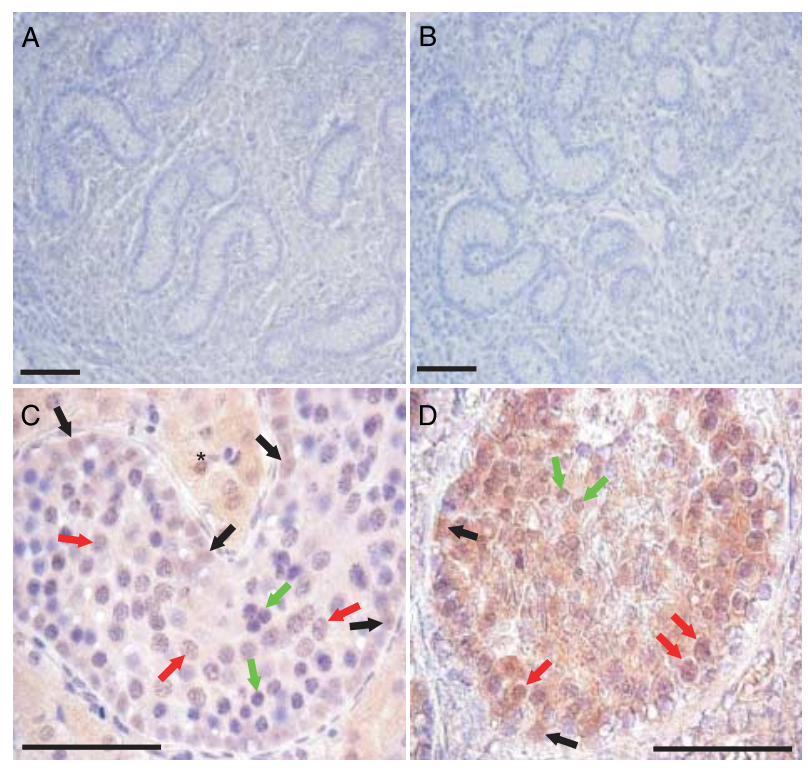

Figure 2 POU5F1 protein expression in developing postnatal pig testis sections. (A) In 2-day-old and (B) 3-week-old testis sections, no expression of POU5F1 protein is detected. (C) In 10-week-old testis, weak POU5F1 expression is seen in spermatogonia (black arrows) and spermatocytes (red arrows). Spermatocytes that are negative for POU5F1 expression appear blue (green arrows). POU5F1 expression is also seen in the interstitial cells (asterisk). In a 20-week-old testis section, POU5F1 expression is mostly seen in the nuclei of spermatocytes (red arrows) and round spermatids (green arrows). A few spermatogonia are also stained (black arrows). Bar $=50 \mu \mathrm{m}$. 
Sections double stained with anti-NANOG antibody and lectin DBA showed that most of the DBA-binding cells and a small number of DBA-negative germ cells expressed NANOG (Fig. 3A-C). Some of the DBApositive cells were also negative for NANOG expression (data not shown). Sections double stained with antiNANOG and anti-ZBTB16 antibodies confirmed that most of the ZBTB16-positive cells expressed NANOG (Fig. 3D-F). NANOG protein was translocated from the nucleus to the perinuclear region and cytoplasm in most germ cells at 1 -week of age (Fig. 3D-F). SSEA-1 expression was seen in testis sections at 2 and 3 weeks of age, at which time NANOG expression was quite weak. In double-stained sections, SSEA- 1 expression was seen in the germ cells that had lost NANOG expression (Fig. 3G-I). In double-stained sections of 20-week-old testes, most of the POU5F1-positive differentiated germ cells expressed NANOG, although not all NANOG expressing cells were necessarily POU5F1 positive (Fig. 3J-L). A small number of POU5F1-positive cells were also negative for NANOG staining. Although POU5F1 staining in germ cells was localized in the nucleus, NANOG staining was detected in both nucleus and cytoplasm. In 20-week-old testis sections, NANOG expression was primarily restricted to differentiated germ cells and was not co-localized with vimentin-expressing somatic cells (Supplementary Fig. 2, which can be viewed online at www.reproduction-online.org/supplemental/).

\section{RT-PCR analysis}

Semi-quantitative RT-PCR analysis showed that the expression of VASA and POU5F1 mRNA was absent in neonatal pig testis (Fig. 4). However, in 20-week-old testis, transcripts of VASA and POU5F1 could be detected.
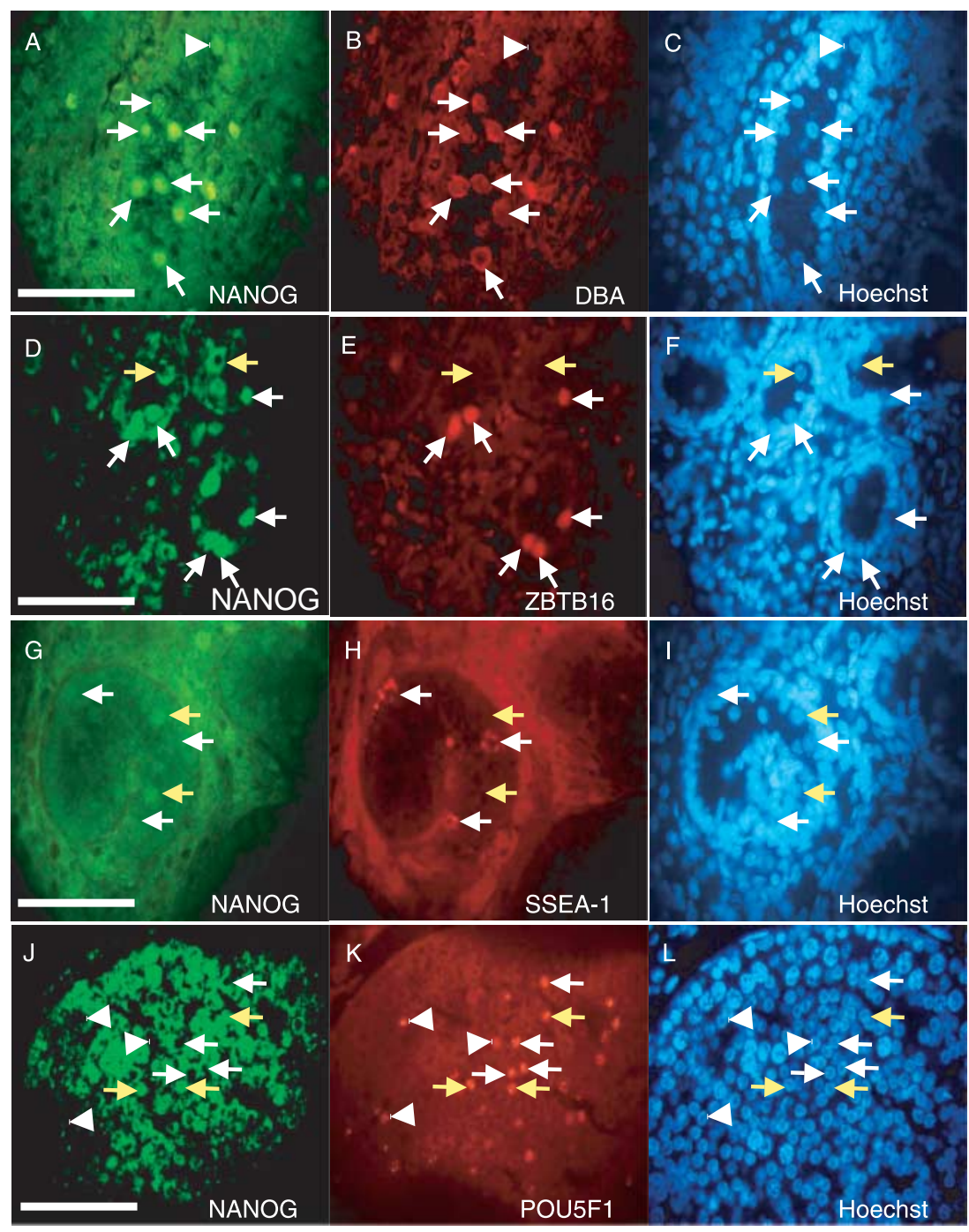

Figure 3 Fluorescence double staining of testis sections. (A and B) A 3-day-old testis section stained with NANOG and DBA. Most DBAbinding cells are positive for NANOG expression (white arrows). NANOG expression is occasionally seen in DBA-negative cells (arrowhead).

(C) The same section stained with Hoechst 33342. (D and E) NANOG and ZBTB16 double staining of a testis section from 1-week-old pig. ZBTB16 expression is visible in most of the NANOGpositive germ cells (white arrows). NANOG protein is localized in the nuclei, perinuclei, and cytoplasm of germ cells at this age. Some germ cells show complete cytoplasmic translocalization of NANOG protein (yellow arrows). (F) The same section stained with Hoechst 33342. ( $\mathrm{G}$ and $\mathrm{H}$ ) Double staining with NANOG and SSEA-1 of a testis section from a 3-week-old pig. SSEA-1 expression is seen in the germ cells that lost NANOG expression (white arrows). Note that the NANOG expression is weak in the 3-weekold section (yellow arrows). (I) The same section stained with Hoechst 33342. (J and K) POU5F1 and NANOG florescence double staining of 20-week-old testis section. Most POU5F1expressing germ cells are positive for NANOG expression (white and yellow arrows). NANOG expression in most of the germ cells is seen in the cytoplasm (white arrows), and in the nuclei of a few germ cells (yellow arrows). Some of the POU5F1-expressing germ cells did not express NANOG (arrowheads). (L) The same section stained with Hoechst 33342. Bar $=50 \mu \mathrm{m}$. 


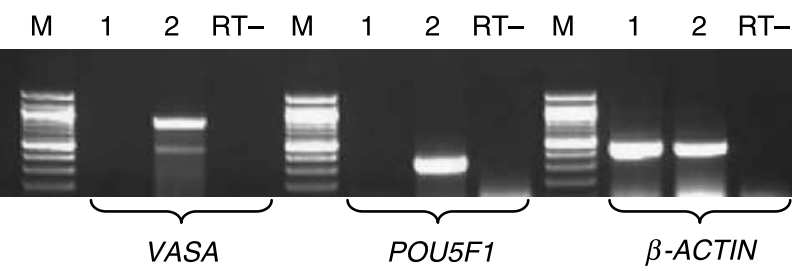

Figure 4 RT-PCR detection of VASA and POU5F1 mRNAs. Total RNA was extracted from neonatal (2- to 7-day old) pig testes and pooled for template (lane 1) and from 20-week-old testis (lane 2). Transcripts of VASA and POU5F1 were detected in 20-week-old testis but not in neonatal testes. $\beta$-ACTIN (ACTB) was used for normalizing RNA samples. RT - , isolated RNA without RT to check genomic DNA contamination; M, 100 bp molecular weight marker.

\section{Analysis of the recipient testis}

To determine the stem cell potential of gonocytes, we transplanted testicular cells from neonatal testes into the testes of immunodeficient mice. One month after transplantation, porcine gonocytes were detected in the seminiferous tubules of the testes of all recipient mice as determined by DBA staining (Fig. 5A). Lectin DBA is a specific marker of porcine gonocytes (Goel et al. 2007) and shows no affinity for mouse testicular cells (Izadyar et al. 2002). Porcine gonocytes not only colonized the recipient testes but also formed chains of cells connected by intercellular bridges, indicating proliferation (Fig. 5B). In some cases, proliferating gonocytes comprised a major part of the basal membrane of the tubules
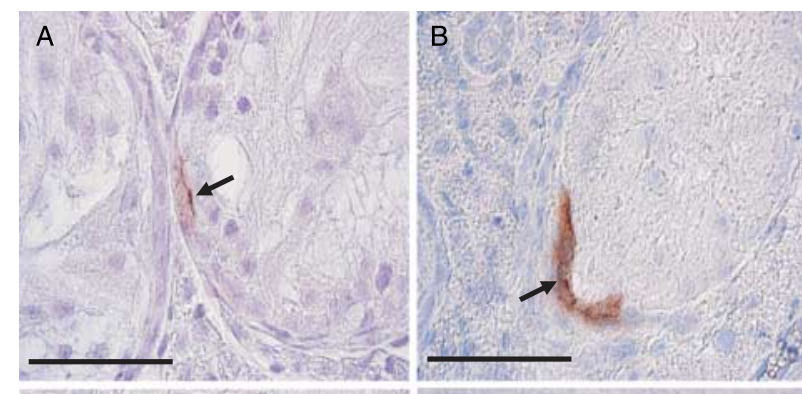

C D

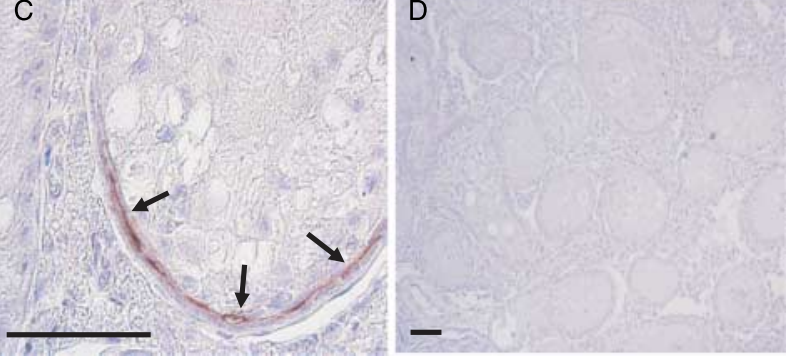

Figure 5 Analysis of the testes of the recipient mice one month after transplantation using a porcine gonocyte-specific marker, Dolichos biflorus agglutinin (DBA). (A) DBA-stained gonocytes that colonized the basal membrane of the recipient testis (arrow). (B) Proliferating gonocytes form a chain-like colony of DBA-positive cells (arrow). (C) In some cases, proliferating porcine gonocytes occupied most of the basal membrane of recipient mouse testes (arrows). (D) No DBA-positive cells are visible in the contralateral testis section. Bar $=50 \mu \mathrm{m}$.
(Fig. 5C). DBA-positive cells were not found in the contralateral control testis (Fig. 5D). The proliferative capacity of colonized porcine gonocytes was further confirmed by DBA-Ki67 double-immunofluorescence staining (Supplementary Fig. 3, which can be viewed online at www.reproduction-online.org/supplemental/). A few DBA-positive cells in testis sections were positive for Ki67 staining. However, some of the DBA-negative cells also expressed Ki67. In transplanted mice testis sections double stained with lectin DBA and anti-Nanog antibody, NANOG expression was detected in the nuclei of all of the DBA-positive germ cells (Fig. 6A-C). However, in some of the colonized DBA-positive germ cells, NANOG expression was either weakened or translocalized to the cytoplasm. Some of the colonized cells were positive for NANOG staining but negative for DBA staining.

\section{Discussion}

Western blot analysis showed that the anti-NANOG and anti-POU5F1 antibodies could identify proteins of definite sizes in the porcine testis. The smaller fragment in NANOG immunoblots indicate towards truncated protein that may have arisen from the cytoplasmic translocalized NANOG. Although amino acid sequences of porcine NANOG (accession no. ABD98822) and porcine POU5F1 (accession no. NP_001106531) show 69 and 88\% homology to mouse NANOG (accession no. Q5TM83) and mouse POU5F1 (accession no. NP_038661) sequences respectively, the sizes of the protein identified by both the antibodies were higher in pigs. Lee et al. (2005) showed that despite $85 \%$ homology between amino acid sequences of mouse and pig VASA, anti-MVH (mouse Vasa homolog) antibody identifies protein of a smaller size $(\sim 65 \mathrm{kDa})$ in pigs. Therefore, it is quite likely that the NANOG and POU 5 F1 proteins have different sizes in pigs.

Our results show that NANOG is expressed in the primitive germ cells of neonatal pig testis. The pattern of expression was strikingly similar to that of the DBA binding in germ cells reported previously (Goel et al. 2007). Strong NANOG expression, like DBA staining, was observed in undifferentiated germ cells until 1 week of age in neonatal testes and was progressively lost with increasing age. At one week of age, many germ cells showed translocation of NANOG protein from the nucleus to the perinuclear region and cytoplasm. NANOG expression was not only specific to germ cells but was also observed in Sertoli and interstitial cells of neonatal testes. Carlin et al. (2006) observed NANOG expression not only in PUC matrix cells but also in porcine fibroblast cell lines. NANOG transcripts were detected not only in the ICM of porcine embryos but also in epiblast-derived somatic cell lines and adult organs (Blomberg et al. 2007). Therefore, NANOG expression, unlike DBA binding, could not be used as a specific marker of pig undifferentiated germ cells in the testis or in 


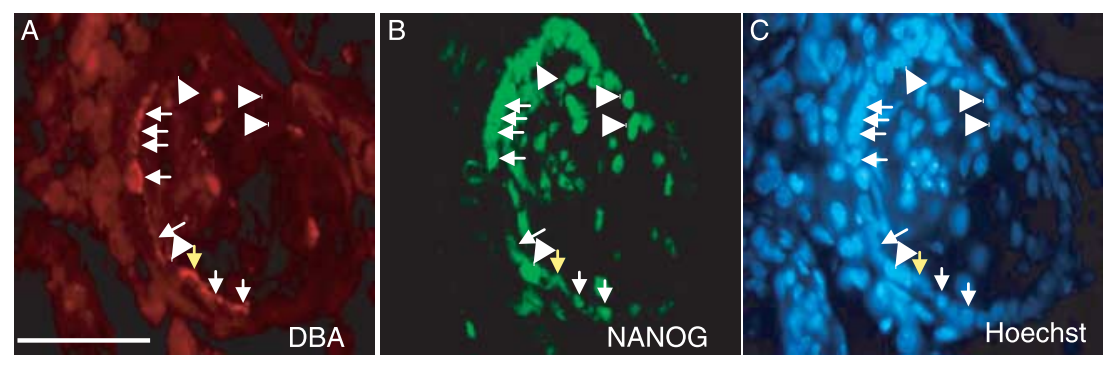

Figure 6 Florescence double staining of transplanted mouse testis with DBA and NANOG. (A and B) Colonized DBA-positive germ cells show nuclear expression of NANOG (white arrows). In some of the DBA-positive cells, the expression was either weaker or seen in the cytoplasm (yellow arrow). Some of the DBA-negative cells also express NANOG (arrowheads). (C) The same section stained with Hoechst 33342. Bar $=50 \mu \mathrm{m}$.

culture. Nevertheless, the expression pattern of NANOG in the postnatal pig testis is a strong indication that it has a role in stem cell activity of undifferentiated germ cells. NANOG expression was co-localized with most of the DBA-binding germ cells in the neonatal pig testes, suggesting that pig gonocytes possess stem cell potential. Lectin DBA is a specific marker for PGCs (Takagi et al. 1997) and gonocytes (Goel et al. 2007) in pigs. NANOG and ZBTB16 expressions were also co-localized in the same germ cells in the neonatal testes. We earlier reported that ZBTB16 expression is restricted specifically to DBA-binding germ cells in neonatal pig testis and to a few undifferentiated spermatogonia in 20-week-old testes (Goel et al. 2007). Since in 20-week-old testes, the numbers of cells that were positive for DBA and ZBTB16 were low, and NANOG expression was quite weak in undifferentiated germ cells, we could not confirm that NANOG-positive spermatogonia were positive for DBA and ZBTB16.

POU5F1 expression was undetected in neonatal pig testes. This is in contrast to the findings in mice, where POU5F1 expression was seen in gonocytes and prospermatogonia in neonatal testes (Pesce et al. 1998b, Tadokoro et al. 2002). POU5F1 expression was seen in 10- and 20-week-old testis sections. At this age, the expression of POU5F1 protein was observed in differentiated germ cells, such as spermatocytes and round spermatids, and in a few undifferentiated spermatogonia. The pattern of POU5F1 expression in 10- and 20-weekold sections was comparable with that of the NANOG expression observed in this report. However, these results are again in disagreement with the findings in mice, where the expression of POU5F1 was restricted to undifferentiated spermatogonia in the testes of the adult mice (Pesce et al. 1998b, Tadokoro et al. 2002). POU5F1 expression was detected in the interstitial cells of 10-week-old testes in this study. Kirchhof et al. (2000) observed POU5F1 expression in both ICM and TE of blastocyst-stage porcine embryos. Similarly, POU5F1 expression was also detected in the primary fibroblast cell line in addition to PUC cells (Carlin et al. 2006). Therefore, it is quite likely that POU5F1 is also expressed by somatic cells. Although NANOG and POU5F1 expressions were co-localized in most of the differentiated germ cells (Fig. 3J-L), many of the NANOGpositive cells were negative for POU5F1 expression.
Therefore, the expressions of POU5F1 and NANOG in pigs are rather unique.

Vasa is a member of the DEAD-box family of genes and encodes an ATP-dependent RNA helicase. In mice, VASA protein is exclusively expressed in PGCs just after their colonization to embryonic gonads and in germ cells undergoing gametogenic processes until the postmeiotic stage in both males and females (Toyooka et al. 2000). However, VASA protein is not detected in pluripotent embryonic cells such as stem and germ cells (Fujiwara et al. 1994). Our results suggest that VASA and POU5F1 expressions in developing pig testes are correlated. POU5F1 expression was absent from neonatal pig testis and was primarily observed in differentiated germ cells such as spermatocytes and round spermatids of prepubertal testis. Similarly, transcripts of VASA were detected in prepubertal testis but not in neonatal pig testis. VASA protein is known to be localized to spermatogenic germ cells such as spermatocytes and round spermatids, but not to elongated spermatids and spermatozoa in the testis of several mammalian species including pig (Toyooka et al. 2000). Lee et al. (2005) showed that VASA protein is expressed by spermatocytes and weakly by spermatogonia in adult pig testis. Tanaka et al. (2000) reported that POU5F1 expression in PGCs of E12.5 was significantly reduced in Vasa null mice, which raises the possibility that POU5F1 expression is under the direct control of VASA function in a stage-specific manner. Therefore, primitive germ cells, such as gonocytes, in neonatal pig testis do not express VASA. It is also possible that VASA expression is co-regulated with POU5F1 expression in developing postnatal porcine testes.

SSEA-1 is known to be expressed in mouse embryos, ES cells (Solter \& Knowles 1978), and in mouse germline stem cells isolated from the neonatal testis (Kanatsu-Shinohara et al. 2004b). SSEA-1 expression in 2- and 3 -week-old testes was detected in germ cells, in which NANOG expression was lost. We previously observed a similar pattern of expression in DBA-binding germ cells (Goel et al. 2007). In other words, SSEA-1 expression was not detected in DBA-positive germ cells and was present only in weakly positive or DBA-negative germ cells in 2- and 3-week-old testes. SSEA-1 expression is not present in adult pig testis (Goel et al. 2007), although it is expressed by porcine PGCs (Takagi et al. 1997) and ICM 
(Wianny et al. 1997) of blastocyst-stage embryos. Our finding therefore suggests that in postnatal pig testis, the expression of pluripotency-specific markers in germ cells is stage specific and varies with age. Our results also suggest that SSEA-1, along with other factors, may be playing a major role in maintaining the pluripotency of germ cells at an age, when NANOG expression is downregulated and POU5F1 expression is absent from germ cells.

The cytoplasmic translocation of NANOG protein in the germ cells with increasing age is interesting because NANOG is a homeodomain-bearing transcription factor and nuclear localization of NANOG is essential for its function. Nuclear export of NANOG may result in the loss of function and quite possibly degradation by cytoplasmic machineries. He et al. (2006) suggested that downregulation of NANOG expression in goat blastocyst occurs by sequestration/degradation utilizing a nucleolar mechanism. Although we failed to identify any such finding in this study, this discrepancy may be due to species difference or a cell-type-specific mechanism that exists in the testis. NANOG expression was detected in somatic cells, such as Sertoli and interstitial cells in the neonatal testes, and the expression was either weak or absent in somatic cells of adult testes. Double staining of 20-week-old testis sections with antivimentin and anti-NANOG antibody confirmed that NANOG was not expressed in somatic cells. This may be due to NANOG is expressed in juvenile/precursor somatic cells such as pre-Sertoli or pre-Leydig cells but not in mature cells.

NANOG expression was detected not only in a few undifferentiated germ cells but also in differentiated germ cells such as spermatocytes in 10- and 20-week-old testis sections. In 20-week-old testis sections, the expression of NANOG protein was variable in the differentiated germ cells, suggesting that the expression pattern was much more dynamic. This is contrary to an earlier finding in mice (Yamaguchi et al. 2005), in which NANOG expression was restricted to PGCs and no germ cells stained positive in the adult testis or ovary. This suggests that the expression pattern of NANOG varies among species. Intriguingly, NANOG protein localization changed from the nucleus to the cytoplasm in the differentiating germ cells in pig testes. In mouse testes, POU5F1 expression has a predominantly nuclear localization in undifferentiated germ cells such as PGCs, gonocytes, and spermatogonia (Ohbo et al. 2003). Upon commitment of SSCs to differentiate, POU5F1 protein becomes cytoplasmically localized and the expression levels fall with the complete absence of expression by the onset of meiosis (Pesce et al. 1998b). Nevertheless, our finding that NANOG and POU5F1 are expressed in the nuclei of spermatocytes and spermatids suggests that these proteins have some role in the meiotic stage of germ cells.

Our finding that NANOG expression was markedly upregulated in the gonocytes but that POU5F1 expression was absent from neonatal pig testis, raised doubts about stem cell potential of gonocytes. Because the stem cells population in male germ cells can only colonize the recipient mouse testis (Brinster \& Zimmermann 1994), we used a testis transplantation technique to assess the stem cell potential of porcine gonocytes. Dobrinski et al. (2000) showed that germ cells from boars aged between 2 days and 6 weeks could colonize and proliferate in the testes of recipient mice. However, there is no information about the stage of germ cells that were transplanted. Moreover, since a species-specific marker for detecting porcine gonocytes was not available at the time of their study, the stem cell potential of porcine gonocytes remains unclear. The testes of the recipient mice were examined for the presence of porcine gonocytes using their specific marker (i.e., lectin DBA; Goel et al. 2007). One month after transplantation, strong DBA-positive germ cells were detected in the testes of the recipient mice. Colonized porcine gonocytes expressed Ki67, a nuclear protein, which is expressed in proliferating cells (Wyns et al. 2007). DBA-positive cells were, however, fewer in the stained section (Supplementary Fig. 3). It is likely that the antigen retrieval process might have weakened the DBA affinity of colonized germ cells. Antigen retrieval was, however, necessary to visualize Ki67 staining in the fixed tissue sections (and also recommended by the manufacturer). These results suggest that porcine gonocytes could proliferate in vivo. Nevertheless, the chain of cells connected by intercellular bridges represents proliferating germ cells in the testes of the xenotransplanted recipient mice (Dobrinski et al. 1999, 2000).

Our results with the transplanted testicular cells from neonatal pig testes are in agreement with the previous report in rat (Orwig et al. 2002a, 2002b), where a subpopulation of pseudopod gonocytes could colonize, proliferate, and maintain colonies of spermatogenesis upon transplantation into the testes of the recipient nude mice. However, we were unable to identify a distinct population of gonocytes, such as pseudopods, in a testicular germ cells prepared from 2- to 4-day pig testes. Our finding differs from an earlier report (McLean et al. 2003), in which mice gonocytes could colonize recipient testes, but they could not proliferate or establish donorderived spermatogenesis. Interestingly, colonized DBApositive cells expressed NANOG, which suggests that NANOG is essential for determining the stem cell potential of gonocytes. However, we detected cells that were DBA negative, but NANOG positive, in the transplanted testes. Because mouse testis does not express NANOG (Yamaguchi et al. 2005), the NANOG-expressing cells represent germ cells from porcine testis that could colonize the recipient testes. DBA-negative germ cells, which express NANOG in neonatal porcine testes, may also possess stem cell potential. Another possibility, namely that the initially DBA-positive germ cells lost DBA affinity in vivo and still retained NANOG expression, could not be ruled out. Nevertheless, these findings confirm that 
neonatal pig testis has a population of stem cells that are capable of colonizing the testes of the mice.

In conclusion, pluripotency-specific proteins, such as NANOG and POU5F1, showed a unique expression pattern in developing postnatal pig testes. NANOG expression was abundant in primitive germ cells of neonatal testis such as gonocytes, and was downregulated in the germ cells at 2 and 3 weeks of age. On the other hand, the expressions of POU5F1 transcripts and protein were undetected in neonatal pig testes. In 10- and 20-week-old testis sections, NANOG and POU5F1 proteins were strongly expressed in differentiated germ cells such as spermatocytes and weakly expressed in spermatogonia. The strong expression of NANOG protein in porcine gonocytes raises the possibility of using the gonocytes to establish a cell line that could have germline characteristics.

\section{Materials and Methods} Collection of testes

All animals in this study were handled according to the guidelines of the Institutional Animal Care and Use Committee of Kyoto University. Testes were collected from crossbred piglets (Landrace $\times$ Large White Yorkshire $\times$ Duroc) aged 2 days to 3 weeks from a local farm. Pigs are castrated at this age to improve their meat quality and growth rate. Testes from 10 - and 20-weekold pigs were collected from a local abattoir. Testicular tissues were fixed immediately after collection in Bouin's fixative and processed for histochemical analysis. For isolation of gonocytes, testes from 2- to 4-day-old piglets were washed in PBS and transported on ice within $2 \mathrm{~h}$ to the laboratory in DMEM/F12 medium (Gibco, Invitrogen) that was supplemented with $100 \mathrm{IU}$ penicillin/ml, $50 \mu \mathrm{g}$ streptomycin $/ \mathrm{ml}, 40 \mu$ g gentamycin sulfate/ml, $250 \mathrm{ng}$ amphotericin B (fungizone)/ml (all from Sigma), and 15 mol HEPES/I (Wako, Osaka, Japan).

\section{Immunoblot analysis}

To demonstrate that anti-NANOG and anti-POU5F1 antibodies, which were raised against mouse antigens, are able to recognize proteins of predicted molecular weight in pigs, Western blot analysis was performed. Total protein lysates from 5-month-old pig testis, and from R1 mouse ES cell line (as a positive control) were prepared in SDS sample buffer. Lysed samples $(15 \mu \mathrm{g})$ were subjected to electrophoresis in $10 \%$ SDSpolyacrylamide gel. The gels were transferred onto polyvinylidene difluoride membrane (Immobilon-P; Millipore, Bedford, MA, USA). The membranes were blocked with $10 \%(\mathrm{w} / \mathrm{v})$ skimmed milk in PBS-Tween (PBS-T; $136 \mathrm{mM} \mathrm{NaCl}, 2.68 \mathrm{mM}$ $\mathrm{KCl}, 8.1 \mathrm{mM} \mathrm{Na} \mathrm{HPO}_{4}, 1.47 \mathrm{mM} \mathrm{KH_{2 }} \mathrm{PO}_{4}$, and $0.1 \%(\mathrm{v} / \mathrm{v})$ Tween-20) for $1 \mathrm{~h}$ at room temperature. The blocked membranes were incubated with a primary antibody, that is, polyclonal rabbit anti-NANOG (Chemicon, Temecula, CA, USA; 1:5000) or monoclonal mouse anti-POU5F1 (OCT3/4; C-10; Santa Cruz Biotechnology, Santa Cruz, CA, USA; 1:1000) in PBS-T containing $10 \%$ skimmed milk overnight at $4{ }^{\circ} \mathrm{C}$.
The membranes were then washed with PBS-T and were incubated with sheep anti-rabbit or sheep anti-mouse HRPconjugated secondary antibody (1:10 000; both from Amersham Biosciences) for $1 \mathrm{~h}$ at room temperature. The blots were visualized using the Immobilon Western chemiluminescence HRP substrate system (Millipore) following exposure to X-ray film (Amersham Biosciences).

\section{Histochemistry}

Fixed testicular samples were dehydrated, embedded in paraffin, and sectioned ( $6 \mu \mathrm{m}$ thick). Dilutions of lectin, primary, and secondary antibodies were done in PBS containing 1\% (w/v) BSA (Sigma). Sections were dewaxed, rehydrated, and stained. Briefly, a testis section was incubated in $15 \%(\mathrm{v} / \mathrm{v})$ normal goat serum in PBS for $15 \mathrm{~min}$, incubated with rabbit anti-NANOG antibody (Chemicon; $1: 200$ ) or mouse anti-POU5F1 (OCT3/4; C-10; Santa Cruz Biotechnology; $1: 50$ ) overnight, at $4{ }^{\circ} \mathrm{C}$ in a moist chamber, rinsed thrice with PBS, incubated with $3 \%(\mathrm{v} / \mathrm{v}) \mathrm{H}_{2} \mathrm{O}_{2}$ (Merck) for 10 min, washed several times with PBS, and then incubated with sheep anti-rabbit or sheep anti-mouse horseradish peroxidase (HRP)-conjugated secondary antibody (1:100; both from Amersham Biosciences) for $1 \mathrm{~h}$ at room temperature, rinsed several times with PBS, incubated for 3-5 min in substrate-chromogen mix containing $2.5 \mathrm{mg}$ 3,3'-diaminobenzidine tetrahydrochloride (Dojindo, Kumamoto, Japan) and $25 \mu \mathrm{l}$ of $3 \%(\mathrm{v} / \mathrm{v}) \mathrm{H}_{2} \mathrm{O}_{2}$ per $5 \mathrm{ml}$ PBS, rinsed thoroughly in distilled water, counterstained with hematoxylin, mounted with Aquatex (Merck), and observed under an Olympus BX 50 microscope. Negative control sections were incubated in $1 \%$ $(w / v)$ BSA in PBS without the primary antibody.

Co-localization of NANOG expression in DBA-binding germ cells was also investigated in the neonatal testis. Briefly, after deparaffinization and rehydration, sections were blocked with $15 \%(\mathrm{v} / \mathrm{v})$ goat serum and $5 \%(\mathrm{w} / \mathrm{v}) \mathrm{BSA}$ in PBS for $30 \mathrm{~min}$. Sections were incubated with anti-NANOG antibody $(1: 200)$ at $4{ }^{\circ} \mathrm{C}$ overnight, washed several times with PBS, incubated with goat anti-rabbit Alexa Fluor 488 (Molecular Probes, Eugene, OR, USA; 1:200) and DBA-rhodamine (Vectors Laboratories; $1: 100$ ) for $1 \mathrm{~h}$ at $37^{\circ} \mathrm{C}$, rinsed thrice with PBS, stained with $1 \mu \mathrm{g} / \mathrm{ml}$ Hoechst 33342 (Sigma) for $10 \mathrm{~min}$, mounted in SlowFade (Molecular Probes), and observed under an Olympus BX 50 microscope fitted with an epifluorescent lamp. In negative controls, the primary antibody and the lectin were omitted. Instead the section was incubated with $1 \%(\mathrm{w} / \mathrm{v})$ BSA in PBS.

Co-immunolocalization of NANOG with ZBTB16 (previously known as PLZF) or SSEA-1 was studied in neonatal pig testes. Twenty-week-old testis sections were double stained to examine co-expression of POU5F1 and NANOG in the germ cells. Further, the sections from 20-week-old testes were double stained with anti-NANOG and anti-vimentin antibodies to ensure that the NANOG expression was restricted to germ cells. Briefly, after deparaffinization, rehydration, and blocking with $15 \%(\mathrm{v} / \mathrm{v})$ goat serum, the sections were co-incubated with anti-NANOG antibody (1:200) along with a primary antibody, that is, mouse anti-ZBTB16 (clone 2A9, 1:100; Santa Cruz Biotechnology), mouse anti-SSEA-1 (anti- 
human CD15, 1:20; DAKO), mouse anti-POU5F1 (1:50), or mouse anti-vimentin (clone V9, 1:100; Sigma) overnight at $4{ }^{\circ} \mathrm{C}$. Sections were washed several times with PBS, incubated with secondary antibodies, that is, goat anti-mouse Alexa Fluor 546 and goat anti-rabbit Alexa Fluor 488 (both from Molecular Probes, $1: 200$ ) for $1 \mathrm{~h}$ at $37{ }^{\circ} \mathrm{C}$, rinsed thrice with PBS, stained with Hoechst 33342, mounted in SlowFade, and observed. Before the sections of the testes were double stained, each of the secondary antibodies that were raised against a species was checked for cross-reactivity with primary antibody of nonreactive species to rule out non-specific binding. In negative controls, primary antibodies were omitted. Instead the section was incubated with $1 \%(\mathrm{w} / \mathrm{v})$ BSA in PBS.

\section{RT-PCR analysis}

Total RNA was prepared from 2- to 7-day-old pig testes, which were pooled for preparing cDNA. RNA was also isolated from 20-week-old testes as a positive control. RNA was isolated using a ToTally RNA kit (Ambion, Inc., Austin, TX, USA) according to the manufacturer's protocol. Extracted RNAs were diluted with diethylpyrocarbonate water and incubated with 2 units of RNase-free DNase (Roche) for $30 \mathrm{~min}$ at room temperature. DNase activity was inhibited by heating the samples at $70{ }^{\circ} \mathrm{C}$ for $15 \mathrm{~min}$ and the samples were stored on ice. Random primers and RNase out (both from Invitrogen) were added to the RNA solution, incubated for $5 \mathrm{~min}$ at $65^{\circ} \mathrm{C}$, and set on ice. For RT, ReverTra Ace (MMLV reverse transcriptase $\mathrm{RNase} \mathrm{H}^{-}$; Toyobo, Osaka, Japan) was added to the RNA solution and incubated for $10 \mathrm{~min}$ at $30^{\circ} \mathrm{C}$, for $60 \mathrm{~min}$ at $42{ }^{\circ} \mathrm{C}$, and for $5 \mathrm{~min}$ at $99^{\circ} \mathrm{C}$ $(\mathrm{RT}+)$. At the same time, the reactions were carried out without the addition of ReverTra Ace to check genomic DNA contamination (RT-). PCR amplification was carried out on $1 \mu \mathrm{l}$ cDNA per $20 \mu \mathrm{l}$ PCR mixture containing $2 \mathrm{mM} \mathrm{MgCl}$, $0.25 \mathrm{mM}$ dNTPs, $1 \times$ PCR buffer, 5 pmol of each primers, and $1 \cup$ Taq DNA polymerase (Ex Taq, Takara, Ohtsu, Japan). The following primers were used for the amplification of specific genes, POU5F1: 5'-AGGTGTTCAGCCAAACGACC3', 5'-TGATCGTTTGCCCTTCTGGC-3', 335 bp (Kues et al. 2005; GenBank accession no. AJ251914; annealing at $60^{\circ} \mathrm{C}$, 35 cycles); VASA: 5'-TGACTTTTGAAGAAGCTAATC-3', 5'-ACCATGAATACTTGTAGTTGA-3', 854 bp (Luo et al. 2006; GenBank accession no. AY626785.1; annealing at $45{ }^{\circ} \mathrm{C}, 35$ cycles); and $\beta$-ACTIN (ACTB): 5'-CGATCCACACAGAGTACTTGCG-3', 5'-CGAGCGTGGCTACAGTTCACC-3', 451 bp (GenBank accession no. NM_001101; annealing at $58{ }^{\circ} \mathrm{C}, 30$ cycles). The PCR products were separated and visualized by $2 \%$ $(\mathrm{w} / \mathrm{v})$ agarose gel electrophoresis containing $0.5 \mu \mathrm{g} / \mathrm{ml}$ ethidium bromide.

\section{Donor cell preparation}

All chemicals were purchased from Sigma-Aldrich, unless mentioned otherwise. Testes collected from piglets aged 2-4 days were treated as described previously (Goel et al. 2007) with some modifications. Briefly, after washing several times with PBS, tunica and other visible connective tissues were removed. Testes were minced with scissors and incubated in DMEM/F12 medium (Gibco, Invitrogen
Corporation) supplemented with $15 \mathrm{~mol} \mathrm{HEPES} / \mathrm{l}, 100 \mathrm{IU}$ penicillin/ml, $50 \mu \mathrm{g}$ streptomycin/ml, $40 \mathrm{mg}$ gentamycin/ml, $1.5 \mathrm{mg}$ collagenase $/ \mathrm{ml}$, and $5 \mu \mathrm{g}$ DNase $/ \mathrm{ml}$ at $35^{\circ} \mathrm{C}$ for $15 \mathrm{~min}$ in a shaking water bath operated at 100 cycles $/ \mathrm{min}$. After three washes with DMEM/F12 medium and the removal of most interstitial cells, fragments of seminiferous tubules were incubated in DMEM/F12 medium containing $1.5 \mathrm{mg}$ collagenase $/ \mathrm{ml}, 1.5 \mathrm{mg}$ hyaluronidase $/ \mathrm{ml}, 0.5 \mathrm{mg}$ trypsin/ml, and $5 \mu \mathrm{g} \mathrm{DNase} / \mathrm{ml}$ for $30 \mathrm{~min}$ in the conditions described above. The dispersed cells were washed twice with medium, suspended in DMEM/F12 medium supplemented with $10 \%$ $(\mathrm{v} / \mathrm{v})$ fetal bovine serum (FBS; JRH Biosciences, Lenexa, KS, USA) and filtered through 80 and $40 \mu$ mylon mesh (Kyoshin Rikou, Tokyo, Japan) successively. The cells were collected by centrifugation at $600 \boldsymbol{g}$ for $5 \mathrm{~min}$. The viability of cells was $>95 \%$ as determined by Trypan blue exclusion. The cells were resuspended in DMEM/F12 medium supplemented with $10 \%(\mathrm{v} / \mathrm{v})$ FBS, $10 \mu \mathrm{g}$ insulin/ml, $10 \mu \mathrm{g}$ apo-transferrin/ml, $100 \mathrm{IU}$ penicillin/ml, $50 \mu \mathrm{g}$ streptomycin/ml, $40 \mu \mathrm{g}$ gentamycin sulfate/ml, single strength non-essential amino acid solution (Gibco, Invitrogen), $1 \mathrm{~mol}$ pyruvate/l, 6 mol lactate/ $\mathrm{I}$, and $200 \mu \mathrm{g}$ DNase/ml to a final concentration of $50-100 \times$ $10^{6}$ cells $/ \mathrm{ml}$.

\section{Recipient mice and donor cell transplantation}

Balb/c nude (nu/nu) mice (Charles River, Yokohama, Japan), aged 8-10 weeks, were used as recipient animals to avoid immunological reaction of donor cells. The mice were kept under specific pathogen-free conditions and food, water, and bedding were autoclaved before use. The mice were housed in $14 \mathrm{~h}$ light:10 $\mathrm{h}$ darkness cycle at constant temperature and provided with food and water ad libitum. At least 4 weeks before donor cell transplantation, the mice were injected busulfan $(35 \mathrm{mg} / \mathrm{kg}$; Sigma) intraperitoneally to deplete endogenous germ cells in the testes (Ji et al. 2007). The recipient mice were anesthetized by i.p. administration of pentobarbital $(50 \mathrm{mg} / \mathrm{kg}$; Nacalai Tesque, Inc., Kyoto, Japan). Testes were exposed through a midline abdominal incision, and $\sim 10-15 \mu \mathrm{l}$ donor cell suspension containing 50-100 $\times 10^{6}$ cells $/ \mathrm{ml}$ was injected through the efferent duct as described previously (Ogawa et al. 1997). Trypan blue $(0.03 \%$ $\mathrm{v} / \mathrm{v}$ ) was added to the injection media that allowed visualization of a successful injection to the seminiferous tubules. Approximately $70-80 \%$ of the surface tubules were filled with each injection. The contralateral testis was used as the negative control.

\section{Analysis of the recipient testis}

One month after donor cell transplantation, the recipient mice were killed by $\mathrm{CO}_{2}$ inhalation, and both testes were removed. Testes were fixed and processed for immunohistochemical analysis as described. Recipient testis sections were analyzed for the presence of porcine gonocytes using DBA staining as described previously (Goel et al. 2007). Briefly, sections were incubated with $3 \%(\mathrm{v} / \mathrm{v}) \mathrm{H}_{2} \mathrm{O}_{2}$ for $10 \mathrm{~min}$, washed with PBS, incubated with $5 \%(\mathrm{w} / \mathrm{v}) \mathrm{BSA}$ in PBS for $15 \mathrm{~min}$, incubated with DBA-conjugated horseradish peroxidase (DBA-HRP, 1:100; EY Laboratories, San Mateo, CA, USA) for $1 \mathrm{~h}$ at $37{ }^{\circ} \mathrm{C}$ in a moist chamber, rinsed thrice with $\mathrm{PBS}$, incubated for $3-5 \mathrm{~min}$ in a 
substrate-chromogen mix, rinsed thoroughly in distilled water, counter stained with hematoxylin, mounted with Aquatex, and observed.

Double immunofluorescence staining of transplanted testis sections was performed with lectin DBA and anti-NANOG antibody as described earlier for sections double stained with DBA-NANOG.

Fluorescence double immunostaining of transplanted testis sections was performed with DBA and anti-Ki67 antibody. The sections were boiled in $10 \mathrm{mM}$ citrate buffer $(\mathrm{pH} 6.0$; Wako) for antigen retrieval for $15 \mathrm{~min}$, followed by cooling at room temperature for $20 \mathrm{~min}$. The sections were then proceeded for immunostaining. Briefly, the section was incubated in $15 \%$ $(\mathrm{v} / \mathrm{v})$ normal goat serum in PBS for $15 \mathrm{~min}$, incubated with rabbit monoclonal anti-Ki67 antibody (1:100; clone SP6, Thermo Fisher Scientific, Fremont, CA, USA) overnight, at $4{ }^{\circ} \mathrm{C}$ in a moist chamber, rinsed thrice with $\mathrm{PBS}$, incubated with goat anti-rabbit Alexa Fluor 488 (1:200) and DBA-rhodamine (1:100) for $1 \mathrm{~h}$ at $37^{\circ} \mathrm{C}$, rinsed thrice with PBS, stained with $1 \mu \mathrm{g} / \mathrm{ml}$ Hoechst 33342 for $10 \mathrm{~min}$, mounted, and observed under a microscope fitted with an epifluorescent lamp. In negative controls, the primary antibody and the lectin were omitted. Instead the section was incubated with $1 \%(\mathrm{w} / \mathrm{v})$ BSA in PBS.

\section{Data processing and analysis}

Testes from at least three animals of a given age were used for histochemical analysis. For gonocyte transplantation, testes were collected from 2- to 4-day-old male piglets from four litters and pooled for the isolation of cells $(n=15)$. Collected cells were injected in recipient nude mice $(n=4)$. The experiment was repeated twice to validate the findings.

\section{Acknowledgements}

We thank Kazuo Kishimoto and Sachiko Kishimoto for providing testis samples. This work was supported by a grant (no. 17658123) from the Ministry of Education, Science, and Culture (MEXT) to $\mathrm{H} \mathrm{I}$. The first author (S G) expresses his gratitude to MEXT for granting a prestigious scholarship that supported his study and stay in Japan. The authors declare that there is no conflict of interest that would prejudice the impartiality of this scientific work.

\section{References}

Blomberg LA, Schreier LL \& Talbot NC 2007 Expression analysis of pluripotency factors in the undifferentiated porcine inner cell mass and epiblast during in vitro culture. Molecular Reproduction and Development $75450-463$.

Brehm A, Ovitt CE \& Schöler HR 1998 Oct-4: more than just a POUerful marker of the mammalian germline? Acta Pathologica, Microbiologica et Immunologica Scandinavica 106 114-124.

Brinster RL \& Zimmermann JW 1994 Spermatogenesis following male germ-cell transplantation. PNAS 91 11298-11302.

Canon S, Herranz C \& Manzanares M 2006 Germ cell restricted expression of chick Nanog. Developmental Dynamics 235 2889-2894.

Capel B 2000 The battle of the sexes. Mechanism of Development 92 89-103.
Carlin R, Davis D, Weiss M, Schultz B \& Troyer D 2006 Expression of early transcription factors Oct4, Sox2 and Nanog by porcine umbilical cord (PUC) matrix cells. Reproductive Biology and Endocrinology 48.

Chambers I, Colby D, Robertson M, Nichols J, Lee S, Tweedie S \& Smith A 2003 Functional expression cloning of Nanog, a pluripotency sustaining factor in embryonic stem cells. Cell $113643-655$.

Degrelle SA, Campion E, Cabau C, Piumi F, Reinaud P, Richard C, Renard JP \& Hue I 2005 Molecular evidence for a critical period in mural trophoblast development in bovine blastocysts. Developmental Biology 288 448-460.

Denning C, Burl S, Ainslie A, Bracken J, Dinnyes A, Fletcher J, King T, Ritchie M, Ritchie WA, Rollo M et al. 2001 Deletion of the alpha (1, 3) galactosyl transferase (GGTA1) gene and the prion protein (PrP) gene in sheep. Nature Biotechnology 19 559-562.

Dobrinski I, Avarbock MR \& Brinster RL 1999 Transplantation of germ cells from rabbits and dogs into mouse testes. Biology of Reproduction 61 1331-1339.

Dobrinski I, Avarbock MR \& Brinster RL 2000 Germ cell transplantation from large domestic animals into mouse testes. Molecular Reproduction and Development 57 270-279.

Donovan PJ \& de Miguel MP 2003 Turning germ cells into stem cells. Current Opinion in Genetics \& Development $13463-471$.

Fujiwara Y, Komiya T, Kawabata H, Sato M, Fujimoto H, Furusawa M \& Noce T 1994 Isolation of a DEAD-family protein gene that encodes a murine homolog of Drosophila vasa and its specific expression in germ cell lineage. PNAS 91 12258-12262.

Goel S, Sugimoto M, Minami N, Yamada M, Kume S \& Imai H 2007 Identification, isolation, and in vitro culture of porcine gonocytes. Biology of Reproduction 77 127-137.

Guan K, Nayernia K, Maier LS, Wagner S, Dressel R, Lee JH, Nolte J, Wolf F, Li M, Engel W et al. 2006 Pluripotency of spermatogonial stem cells from adult mouse testis. Nature 440 1199-1203.

Hamra FK, Gatlin J, Chapman KM, GrellhesI DM, Garcia JV, Hammer RE \& Garbers DL 2002 Production of transgenic rats by lentiviral transduction of male germ-line stem cells. PNAS 99 14931-14936.

Hamra FK, Chapman KM, Nguyen DM, Williams-Stephens AA, Hammer RE \& Garbers DL 2005 Self renewal, expansion, and transfection of rat spermatogonial stem cells in culture. PNAS 102 17430-17435.

Hart AH, Hartley L, Ibrahim M \& Robb L 2004 Identification, cloning and expression analysis of the pluripotency promoting Nanog genes in mouse and human. Developmental Dynamics 230 187-198.

Hatano SY, Tada M, Kimura H, Yamaguchi S, Kono T, Nakano T, Suemori H, Nakatsuji N \& Tada T 2005 Pluripotential competence of cells associated with Nanog activity. Mechanism of Development 122 67-79.

He S, Pant D, Schiffmacher A, Bischoff S, Melican D, Gavin W \& Keefer C 2006 Developmental expression of pluripotency determining factors in caprine embryos: novel pattern of NANOG protein localization in the nucleolus. Molecular Reproduction and Development 73 1512-1522.

Hughes PE \& Varley MA 1980. Puberty in the male. In Reproduction in the Pig, edn 1, pp 173-186. London: Butterworth and Co. Ltd.

Izadyar F, Spierenberg GT, Creemers LB, den Ouden K \& de Rooij DG 2002 Isolation and purification of type A spermatogonia from the bovine testis. Reproduction 124 85-94.

Ji M, Minami N, Yamada M \& Imai H 2007 Effect of protopanaxatriol saponin on spermatogenic stem cell survival in busulfan-treated male mice. Reproductive Medicine and Biology 6 99-108.

Kanatsu-Shinohara M, Toyokuni S \& Shinohara T 2004a Transgenic mice produced by retroviral transduction of male germ line stem cells in vivo. Biology of Reproduction 71 1202-1207.

Kanatsu-Shinohara M, Inoue K, Lee J, Yoshimoto M, Ogonuki N, Miki H, Baba S, Kato T, Kazuki Y, Toyokuni S et al. 2004b Generation of pluripotent stem cells from neonatal mouse testis. Cell 119 1001-1012.

Kanatsu-Shinohara M, Miki H, Inoue K, Ogonuki N, Toyokuni S, Ogura A \& Shinohara T 2005 Long-term culture of mouse male germline stem cells under serum- or feeder-free conditions. Biology of Reproduction 72 985-991.

Kanatsu-Shinohara M, Ikawa M, Takehashi M, Ogonuki N, Miki H, Inoue K, Kazuki Y, Lee J, Toyokuni S, Oshimura M et al. 2006 Production of knockout mice by random or targeted mutagenesis in spermatogonial stem cells. PNAS 103 8018-8023.

Kirchhof N, Carnwath JW, Lemme E, Anastassiadis K, Schöler H \& Niemann H 2000 Expression pattern of Oct-4 preimplantation embryos of different species. Biology of Reproduction 63 1698-1705. 
Kubota H, Avarbock MR \& Brinster RL 2004 Culture conditions and single growth factors affect fate determination of mouse spermatogonial stem cells. Biology of Reproduction 71 722-731.

Kues WA, Petersen B, Mysegades W, Carnwath JW \& Niemann H 2005 Isolation of murine and porcine fetal stem cells from somatic tissue. Biology of Reproduction 72 1020-1028.

Kumar BM, Jin HF, Kim JG, Ock SA, Hong Y, Balasubramanian S, Choe SY \& Rho GJ 2007 Differential gene expression patterns in porcine nuclear transfer embryos reconstructed with fetal fibroblasts and mesenchymal stem cells. Developmental Dynamics 236 435-446.

Kuroiwa Y, Kasinathan P, Matsushita H, Sathiyaselan J, Sullivan EJ, Kakitani M, Tomizuka K, Ishida I \& Robl JM 2004 Sequential targeting of the genes encoding immunoglobulin-mu and prion protein in cattle. Nature Genetics 36 775-780.

Lai L, Kolber-Simonds D, Park KW, Cheong HT, Greenstein JL, Im GS, Samuel M, Bonk A, Rieke A, Day BN et al. 2002 Production of Alpha 1, 3 -galactosyltransferase knockout pigs by nuclear transfer cloning. Science 295 1089-1092.

Lee GS, Kim HS, Lee SH, Kang MS, Kim DY, Lee CK, Kang SK, Lee BC \& Hwang WS 2005 Characterization of pig vasa homolog gene and specific expression in germ cell lineage. Molecular Reproduction and Development $72320-328$.

Luo J, Megee S, Rathi R \& Dobrinski I 2006 Protein gene product 9.5 is a spermatogonia-specific marker in the pig testis: application to enrichment and culture of porcine spermatogonia. Molecular Reproduction and Development 73 1531-1540.

McCreath KJ, Howcroft J, Campbell KHS, Colman A, Schnleke AE \& Kind AJ 2000 Production of gene-targeted sheep by nuclear transfer from cultured somatic cells. Nature 405 1066-1069.

McLean DJ, Friel PJ, Johnston DS \& Griswold MD 2003 Characterization of spermatogonial stem cell maturation and differentiation in neonatal mice. Biology of Reproduction 69 2085-2091.

Mitsui K, Tokuzawa Y, Itoh H, Segawa K, Murakami M, Takahashi K, Maruyama M, Maeda M \& Yamanaka S 2003 The homeoprotein Nanog is required for maintenance of pluripotency in mouse epiblast and ES cells. Cell 113 631-642.

Moore TJ, de Boer-Brouwer M \& van Dissel-Emiliani FM 2002 Purified gonocytes from the neonatal rat form foci of proliferating germ cells in vitro. Endocrinology 143 3171-3174.

Nagano M, Avarbock MR, Leonida EB, Brinster CJ \& Brinster RL 1998 Culture of mouse spermatogonial stem cells. Tissue and Cell $\mathbf{3 0}$ 389-397.

Nagano M, Shinohara T, Avarbock MR \& Brinster RL 2000 Retrovirus-mediated gene delivery into male germ line stem cells. FEBS Letters 475 7-10.

Nagano M, Brinster CJ, Orwig KE, Ryu BY, Avarbock MR \& Brinster RL 2001 Transgenic mice produced by retroviral transduction of male germline stem cells. PNAS 98 13090-13095.

Nagano M, Ryu BY, Brinster CJ, Avarbock MR \& Brinster RL 2003 Maintenance of mouse male germ line stem cells in vitro. Biology of Reproduction 68 2207-2214.

Oatley JM, de Avila DM, McLean DJ, Griswold MD \& Reeves JJ 2002 Transplantation of bovine germinal cells into mouse testes. Journal of Animal Science 80 1925-1931.

Ogawa T, Aréchaga JM, Avarbock MR \& Brinster RL 1997 Transplantation of testis germinal cells into mouse seminiferous tubules. International Journal of Developmental Biology 41 111-122.
Ohbo K, Yoshida S, Ohmura M, Ohneda O, Ogawa T, Tsuchiya H, Kuwana T, Kehler J, Abe K, Scholer HR et al. 2003 Identification and characterization of stem cells in prepubertal spermatogenesis in mice. Developmental Biology 258 209-225.

Orwig KE, Avarbock MR \& Brinster RL 2002a Retrovirus-mediated modification of male germline stem cells in rats. Biology of Reproduction $67874-879$

Orwig KE, Ryu BY, Avarbock MR \& Brinster RL 2002b Male germ-line stem cell potential is predicted by morphology of cells in neonatal rat testes. PNAS 99 11706-11711.

Ovitt CE \& Schöler HR 1998 The molecular biology of Oct-4 in the early mouse embryo. Molecular Human Reproduction 4 1021-1031.

Pesce M, Gross MK \& Schöler HR 1998a In line with our ancestors: Oct-4 and the mammalian germ. Bioessays $20722-732$.

Pesce M, Wang X, Wolgemuth DJ \& Scholer H 1998b Differential expression of the Oct-4 transcription factor during mouse germ cell differentiation. Mechanism of Development 71 89-98.

De Rooji DG \& Russell LD 2000 All you wanted to know about spermatogonia but were afraid to ask. Journal of Andrology 21 776-798.

Solter D \& Knowles BB 1978 Monoclonal antibody defining a stage-specific mouse embryonic antigen (SSEA-1). PNAS 75 5565-5569.

Surani MA 2001 Reprogramming of genome function through epigenetic inheritance. Nature 414 122-128.

Tadokoro Y, Yomogida K, Ohta H, Tohda A \& Nishimune Y 2002 Homeostatic regulation of germinal stem cell proliferation by the GDNF/FSH pathway. Mechanism of Development 113 29-39.

Takagi Y, Talbot NC, Rexroad CE Jr \& Pursel VG 1997 Identification of pig primordial germ cells by immunocytochemistry and lectin binding. Molecular Reproduction and Development 46 567-580.

Tanaka SS, Toyooka Y, Akasu R, Katoh-Fukui Y, Nakahara Y, Suzuki R, Yokoyama M \& Noce T 2000 The mouse homolog of Drosophila Vasa is required for the development of male germ cells. Genes and Development 14 841-853.

Toyooka Y, Tsunekawa N, Takahashi Y, Matsui Y, Satoh M \& Noce T 2000 Expression and intracellular localization of mouse Vasa-homologue protein during germ cell development. Mechanism of Development 93 139-149.

Wang SH, Tsai MS, Chiang MF \& Li H 2003 A novel NK-type homeobox gene, ENK (early embryo specific NK), preferentially expressed in embryonic stem cells. Gene Expression Patterns 3 99-103.

Wianny F, Perreau C \& Hochereau de Reviers MT 1997 Proliferation and differentiation of porcine inner cell mass and epiblast in vitro. Biology of Reproduction $\mathbf{5 7}$ 756-764.

Wyns C, Curaba M, Martinez-Madrid B, Van Langendonckt A, FrançoisXavier W \& Donnez J 2007 Spermatogonial survival after cryopreservation and short-term orthotopic immature human cryptorchid testicular tissue grafting to immunodeficient mice. Human Reproduction 22 1603-1611.

Yamaguchi S, Kimura H, Tada M, Nakatsuji N \& Tada T 2005 Nanog expression in mouse germ cell development. Gene Expression Patterns $\mathbf{5}$ 639-646.

Received 23 October 2007

First decision 5 December 2007

Revised manuscript received 28 February 2008

Accepted 14 March 2008 